\title{
A comparison of nerve conduction velocities and current perception thresholds as correlates of clinical severity of diabetic sensory neuropathy
}

\author{
MARC S RENDELL,* JEFFERSON J KATIMS, $\uparrow$ RALPH RICHTER, \\ FAITH ROWLAND $\ddagger$ \\ From the Creighton University School of Medicine, ${ }^{*}$ Omaha, Neb, New York Medical College, $\dagger$ Cabrini \\ Medical Center, $\dagger$ Valhalla, NY, and Tulsa Medical College $\ddagger$ Tulsa, Ok, USA
}

SUMMARY Nerve conduction velocities (NCVs) are the standard measurements used to confirm the presence or absence of diabetic neuropathy. NCVs were contrasted with the newer technique of measurement of alternating current perception thresholds (CPTs) in assessing the quantitative level of correlation with severity of diabetic sensory neuropathy. A very detailed, scored neurological history (symptoms) and physical examination, emphasising sensory assessment, was conducted on 71 individuals with diabetic neuropathy of varying degrees of severity. Sensory and motor NCVs and CPTs at 5,250 , and $2000 \mathrm{~Hz}$ of the upper and lower extremities were determined for these individuals. In addition, vibration thresholds (VTs) were measured as a third modality. Twenty eight individuals underwent repeated evaluations at 2, 6, 10 and 12 months after the initial procedures. Using the results of 169 complete evaluations, correlations were determined between physical scores (PS) and symptom scores (SS) and NCVs. NCV correlations with the SS were weaker than with the PS. The strongest of the correlations were found between the PS and motor NCVs of the median nerve (rho $=$ 0.29 ) and the tibial nerve (rho $=0.38$ ). Normal NCVs were present in the face of very significant historical and physical abnormality. Correlations of the SS and PS with both VTs and CPTs were higher than with the NCVs. CPTs proved the more effective as predictors of both symptomatic and physical impairment. NCVs appear to lack the resolving power necessary to evaluate subtle differences in clinical state of diabetic sensory neuropathy. The supplementary use of current perception testing may improve the quantitative assessment of this condition.

Peripheral sensory neuropathy is one of the most common long term complications of diabetes mellitus occurring in about $50 \%$ of patients with diabetes of 25 years duration. ${ }^{\prime}$ A careful history and physical examination documenting pain and paraesthetic symptoms and impairment of pain, temperature, vibratory, and light touch sensation is the cornerstone of diagnosis of this condition. However, quantitative criteria are necessary to permit comparative distinctions to be made in serial follow-up of individual patients. The need is made more imperative by the advent of clinical trials of aldose reductase inhibitors

Address for reprint requests: $\mathrm{Dr} M \mathrm{~S}$ Rendell, MD, The Creighton Diabetes Center, 601 North 30th Street, Omaha, Nebraska 68131, USA.

Received 19 July 1988.

Accepted 6 September 1988 and other agents with the potential of improving and even reversing symptomatic diabetic neuropathy. We have compared current perception thresholds (CPTs) with nerve conduction velocities (NCVs) as parametric indicators of diabetic sensory neuropathy.

Nerve conduction testing (NCT) is the classical technique used for diagnosis of diabetic neuropathy. The diagnostic interpretation of the compound action potentials evoked in the standard NCT includes the analysis of changes in sensory and motor nerve conduction velocities (NCVs), response amplitudes, and latencies. Of these measurements, NCVs are the most reproducible and subject to standardisation. Therefore NCVs have become the quantitative hallmark of the extent and progression of impairment in diabetic peripheral neuropathy. ${ }^{2-7}$ However, the degree of correlation between NCVs and the clinically observable parameters of severity of diabetic sensory neuropathy has never been established. The question 
is: how well do NCVs reflect the symptoms of pain and numbness and the loss of physical sensation which characterise diabetic sensory neuropathy? The standard measurement of peripheral nerve conduction velocity is largely determined by the state of the largest, most rapidly conducting myelinated fibres. ${ }^{8}$ However, the pathophysiological lesions of diabetic neuropathy involve a broad spectrum of nerve fibres of varying diameter, with coexisting processes of demyelination and remyelination..$^{9-12}$ Painful diabetic sensory neuropathy, in particular, is related more specifically to changes in unmyelinated and small myelinated fibres. ${ }^{13}$ Therefore, there is considerable uncertainty that NCVs adequately represent the pathological and clinical changes of diabetic sensory peripheral neuropathy. ${ }^{14}$

CPT testing is relatively new in the assessment of sensory neuropathy, although the perception of electrical stimulation of sensory nerves with skin electrodes is not. ${ }^{15-32}$ Physiologically, current perception appears to represent direct stimulation of myelinated and unmyelinated nerve fibres in the skin. ${ }^{33-35}$ Nerve conduction testing uses supramaximal stimuli, thereby recruiting all available fibres, and therefore assesses whole nerve bundle conduction more than individual fibre integrity. In contrast, CPT testing relies on minimal stimuli and thus is dependent on local integrity of nerve endings as well as conduction. Electrocutaneous perception seems to correlate best with the applied current rather than the voltage. ${ }^{.7-19}$ However, the reproducible application of current requires standardisation of skin impedance, ${ }^{19-21}$ which is difficult to achieve since skin resistance and impedance vary considerably with applied current. ${ }^{28-32}$ These variations previously made it difficult to quantitatively relate applied current to sensory threshold. However, the recent deve upment of a multiple frequency alternating current transcutaneous electric nerve stimulation device with constant current feedback control circuits ${ }^{36}$ has made it possible for the first time to obtain CPTs in a quantitative, reproducible manner. The utility of this new CPT testing technique in screening for neuropathy has been demonstrated. ${ }^{37}$ In recent studies, it has shown promise as a technique for quantitation of peripheral neuropathy. ${ }^{38}$

In the serial assessment of diabetic sensory neuropathy, it is essential to use techniques of quantitation which accurately reflect the clinical progression of this condition. The present study provides a comprehensive comparison of NCVs and CPTs as correlates of the clinical severity of diabetic sensory neuropathy. In addition, vibration threshold (VT) testing was simultaneously used as a third contrast technique. The use of an electric vibrator to quantitate VTs is a long established technique. ${ }^{39}$ The determination of VTs has proven effective in the evaluation of diabetic neuropathy, correlating better with physical signs of neuropathy than with symptomatic complaints. $^{40}$ The vibratory threshold (VT) using this technique has been shown to correlate with motor nerve conduction velocity in diabetics. ${ }^{41}$

\section{Methods}

Patient Selection: Diabetic patients were carefully interviewed to eliminate any potential interfering neurological conditions. Exclusion factors included a significant history of alcohol ingestion, thyroid disease, symptoms suggestive of cervical or lumbar disc disease or nerve root irritation, occupational exposure to neurotoxins, or history of significant trauma potentially damaging to peripheral innervation. Any patient with a serum creatinine greater than $2 \cdot 0$ $\mathrm{mg} / \mathrm{dl}$ or abnormal serum vitamin B12 or VDRL levels was excluded from the study. All patients requiring treatment of their neuropathy with anything other than a non-narcotic analgesic were excluded from the study.

Clinical Evaluation: Assessments were carried out by one examiner. A second examiner carried out independent evaluations without prior knowledge for verification. The historica! evaluation was adapted (so as to focus very specifically on sensory complaints) from the Neurological Symptom Score (NSS) proposed by Dyck et $a t^{2}$ for evaluation of peripheral neuropathy. Patients were questioned as to symptoms on the upper and lower extremities. They were asked to describe their symptoms as either painful or nonpainful with further breakdown of pain into "burning," "deep aching," "shooting," "tenderness," or other pain. Non-painful symptoms were "numbness," "asleep feeling," prickling," "tingling," "pins and needles," or other paraesthesiae. Inability to maintain balance or carry out fine activities due to lack of feeling were indicative of loss of proprioception. They were carefully questioned as to the severity of their symptoms, characterising each complaint as either absent (Grade 0$)$, mild (1-2), moderate (3-6), severe (7-8), or very severe $(9,10)$. The examiner asked further questions to confirm the patient's perception of severity, including whether the pain kept the patient up at night, whether contact such as bed covers could be tolerated, if pain medication was used, or if the patient had been burned or injured as a result of absence of aversive perception. The examiner then assigned the final grade to each symptom and separately characterised the symptomatic score (SS) for the upper extremity and for the lower extremity on a scale of 0 to 10 .

The neurologic physical examination was carried out in standard fashion as described in the Neurological Disability Score (NDS) of Dyck et $a l^{\mu^{2}}$ with special emphasis on the sensory portion of the examination. Light touch was assessed with a wisp of cotton, pain via pin prick sensation, and thermal sensation by the touch of cold metal. Vibratory perception was tested with a $256 \mathrm{~Hz}$ aluminium tuning fork. The NDS only considers the index finger and great toe for test sites. This was judged to be insufficient adequately to characterise the level of sensory impairment. Therefore testing was systematically carried out sequentially at six sites on the upper and lower extremities (table 1). Response was scored at each site as 0 (normal), $1+$ (mild impairment of perception), $2+$ (moderate impairment), $3+$ (minimal perception), and $4+$ (complete absence of sensation). The 
Table 1 Test sites for physical examination Light Touch, Pinprick, and
Thermal Vibratory

Upper Extremity: index finger below base of nail distal half of hand proximal half of hand wrist midarm

elbow

Lower Extremity: great toe below base of nail distal half of foot proximal half of foot ankle midleg knee

The locations for testing with each of the sensory modalities are given. Response was scored for each modality at each site: 4 points for total absence of perception, 3 points for minimal perception, 2 points for moderate blunting of perception, 1 point for minima blunting of perception, 0 points for normal perception. Points for each perceptual modality at each site were summed to obtain a tota score on the upper or lower extremity. Normal was defined as a total of 0 , mild abnormality was scored at 16 , moderate abnormality 17 47 , and severe abnormality 48 and above.

physical score (PS) for upper and lower extremities was calculated by adding the scores for the four sensory modalities at each site on the patient's left side. Any patient with significant asymmetry on the clinical examination was excluded from further study. The neurological physical examinations were characterised for upper and lower extremities as either normal, mildly abnormal, moderately abnormal, or severely abnormal. Normal was defined as a total score of 0 . Mild abnormality was defined as no greater than a $2+$ impairment on the finger tips or toes and no more than a $1+$ impairment on distal and proximal halves of hand or foot, thus corresponding to a PS no greater than 16 . Severe abnormality was characterised as total absence of perception to the four physical modalities on the upper extremity at least up to the wrist or, on the lower extremity, at least up to the ankle. This corresponded to a total PS of at least 48 . Moderate abnormality was classified as a PS between 17 and 47.

Nerve Conduction Testing: Nerve conduction testing was carried out on each subject's left side using standard techniques. ${ }^{43}$ A Cavan Model 600 dual channel electromyograph was used. A supramaximal stimulus of 100 to 300 volts of $0 \cdot 1$ to $0.5 \mathrm{~ms}$ duration was applied using surface electrodes at a frequency of $1 / \mathrm{s}$. Motor conduction velocities were determined for the median nerve (NCVM), the ulnar nerve (NCVU), the tibial (NCVTIB) and peroneal nerves (NCVPER), calculated by dividing the distance between proximal and distal stimulating cathodes by the latency. Sensory potentials were calculated by dividing the distance between stimulating and recording cathodes by response latency. The results were calculated on the basis of average of ten or more responses. The median sensory nerve conduction velocity (NCSMED) was obtained using orthodromic stimulation, and the sural sensory nerve velocity (NCS) using antidromic stimulation. Skin temperature was maintained using infrared heating or warming blankets between $33^{\circ}$ and $35^{\circ} \mathrm{C}$, determined using specially designed liquid crystal thermometers
(Seven Cs, St. Louis, Missouri), with accurate gradations of $0.5^{\circ} \mathrm{C}$ positioned on several places on arm or leg. Nerve conduction testing is subject to significant variability, despite the standardisation of procedures. Whenever possible, nerve conduction velocities were repeated twice within three days and the averaged values taken as the result.

Vibration Threshold Testing: The technique was as originally described by Goldberg and Lindblom. ${ }^{44}$ The vibratory threshold was determined at three sites on the left side: (a) the dorsum of the second metacarpal (carpal site, VCAR), (b) the flat surface of the proximal part of the tibia (tibial plateau, VTIB), and (c) the dorsomedial aspect of the first metatarsal bone (tarsal site, VTAR). The vibration testing device (Biothesiometer, Bio-Medical Instruments, Newbury, Ohio) was hand applied to each site with the pressure of its own weight $(450 \mathrm{~g})$. The vibration threshold (VT) was determined by the method of limits. Stimulus strength was incremented gradually from zero to the point where sensation was first perceived (vibration perception threshold measured in millivolts). The stimulus was then decreased to the point where the sensation first disappeared (vibration disappearance threshold). This procedure was repeated three times. The average of the three perception and disappearance thresholds was calculated as the VT.

Current perception thresholds: A portable battery (6 volts) operated transcutaneous nerve stimulator [Neurometer(tm) manufactured by Neurotron Inc, 6211 Falls Road, Baltimore, Maryland 21209] was used. The device emits graded sinusoidal alternating current stimulus at 5,250 , and $2000 \mathrm{~Hz}$ at intensities from 0 to maximal level of 10 milliamperes maintained at a constant current by feedback circuits, irrespective of applied impedance. The maintenance of constant current at each intensity through variable resistors was verified by oscilloscopic measurement.

The current was delivered to the skin surface via a pair of 1 $\mathrm{cm}$ diameter standard carbon electrodes separated by $1.7 \mathrm{~cm}$. A light covering of standard electrode paste applied to the electrode was used as a conducting medium between the electrodes and the underlying skin. Care was taken to ensure that only the skin directly underlying each electrode was in contact with the paste while the surrounding skin areas remained dry with no electrode paste.

Two test stimulation sites on the left side were selected: the dorsal surfaces of the distal phalanges of the index finger and the great toe. Each subject was seated in a quiet area and asked to concentrate on the testing procedure. At each frequency, the current was progressively incremented until the subject could first perceive the sensation. The current was then rapidly decreased and increased until the same threshold measure was obtained on at least five consecutive trials to establish the threshold. The result was also verified with placebo stimulation by turning off all current, unknown to the patient, to challenge the patient's reported sensation at threshold, a procedure known as "forced choice". The thresholds on the hand at the three frequencies are named H5, H250, and H2000, those on the foot, FT5, FT250, and FT2000.

Statistical Analysis: Neurological examinations were carried out together with electrodiagnostic testing initially and repeated sequentially at intervals in consenting participants. Each evaluation was treated as an independent event with no reference to prior measures. Non-parametric correlation analysis (Spearman rho) was performed as a measure of 
association $^{45}$ of symptom and physical scores with the various electrodiagnostic variables. Class comparisons were carried out using non-parametric analysis of variance (Kruskal-Wallis). Values for each electrodiagnostic parameter were classified as either within the normal range (Class I) or abnormal (Class II). In order to evaluate the contribution of highly abnormal or unobtainable electrodiagnostic measures, the abnormal range was subdivided by defining an arbitrary limit for "very abnormal values". For NCVs, this limit was defined as $10 \mathrm{~m} / \mathrm{s}$ or more below the lower end of the normal range. VTs greater than 35 volts and CPTs greater than $9 \mathrm{mAmp}$ were similarly classified. All unobtainable measures were assigned to the "very abnormal" group (Class IIb).

\section{Results}

There were 71 individuals who participated in this study, 36 men, average age 51, SD 3, and 35 women, average age 54, SD 2 years. This group underwent 169 comprehensive evaluations consisting of a neurological history and physical examination, nerve conduction testing, CPT, and VT measurements. There were 36 persons who had multiple serial comprehensive evaluations. Of this group, 28 underwent repeated evaluations $2,6,10$, and 12 months after the initial evaluation. Repeat assessments in time were treated as fully independent events, without reference to previous evaluations.

The study population exhibited a wide spectrum of severity of sensory neuropathy, classified as being of either normal, mild, moderate, or severe degree on the basis of detailed grading of symptoms and physical exam (table 2). Generally physical findings were relatively more severe than symptomatic reports, and both tended to be more severe for the lower extremity than for the upper extremity. Classified either on the basis of symptomatic or physical findings, the majority of evaluations were in the "mild" or "moderate" categories on the upper extremity while falling into the "moderate" or "severe" categories on the lower extremity. This is in keeping with the usual stocking predominance of diabetic neuropathy.

The correlation of symptoms on upper and lower extremities (Spearman rho $=0.65$ ) was better than the cross correlations of symptoms with physical findings on either upper or lower extremity (table 3). Similarly, the correlation of physical findings on upper and lower extremities $(0.63)$ was better than the cross correlations. Correlations with glycohaemoglobin values were weak.

Spearman correlation coefficients between the NCVs and the SS and PS on upper and lower extremities are presented in table 4. Although most correlations were significant, the coefficients were relatively weak, particularly for the correlations of symptom scores with the motor NCVs. The sensory
NCVs correlated somewhat better with symptom scores than with physical scores.

Both vibration thresholds and CPTs showed better correlations with the PS than with the SS on both upper and lower extremities (table 5), and correlation coefficients were generally higher than for NCVs. The highest correlations were exhibited between the CPT values and the PS on the lower extremity, with rho values greater than 0.5. Correlations of VTs with PS were higher than the corresponding NCV correlations, but generally less than the CPT correlations. On the lower extremity, there was not a significant correlation between VTs and SS.

Although significant, the degrees of correlation between NCVs and clinical scores did not appear to be sufficient to create adequate distinctions of level of clinical impairment. In particular, NCVs in the normal range were present in patients with both marked symptoms and physical findings of sensory neuropathy, and abnormal NCVs were not necessarily accompanied by significant clinical abnormalities. The SS and PS corresponding to normal NCV values (Class I) were compared to SS and PS corresponding to abnormal values (Class II). On the upper extremity (table 6), clinical scores were poorly separated by the two NCV classes. Symptom scores did not show any significant differences. There was a small difference

Table 2 Percentage distribution of severity of symptom and physical scores for upper and lower extremity in the study population

\begin{tabular}{lcclc}
\hline & Normal & Mild & Moderate & Severe \\
\hline Upper Extremity: & & & & \\
$\quad$ Symptoms & $25 \%$ & $32 \%$ & $33 \%$ & $10 \%$ \\
$\begin{array}{l}\text { Physical } \\
\text { Lower Extremity: }\end{array}$ & $6 \%$ & $29 \%$ & $58 \%$ & $7 \%$ \\
$\begin{array}{l}\text { Symptoms } \\
\text { Physical }\end{array}$ & $5 \%$ & $26 \%$ & $47 \%$ & $22 \%$ \\
\hline
\end{tabular}

The percentage of the study population falling into either normal mild, moderate or severe categories of neurological history and physical evaluation are given for the upper extremity and for the lower extremity.

Table 3 Spearman correlation of symptom and physical scores: Scores for symptoms (SYM) and physical exam (PHYS) were correlated for upper extremity (UE) and lower extremity ( $L E)$

\begin{tabular}{|c|c|c|c|}
\hline $\begin{array}{l}\text { UE SYM:LE } \\
\text { SYM } \\
0.62 \ddagger\end{array}$ & $\begin{array}{l}\text { UE SYM:UE } \\
\text { PHYS } \\
0 \cdot 47 \ddagger\end{array}$ & $\begin{array}{l}\text { LE SYM:LE } \\
\text { PHYS } \\
0.42 \ddagger\end{array}$ & $\begin{array}{l}\text { UE PHYS:LE } \\
\text { PHYS } \\
0.62 \ddagger\end{array}$ \\
\hline $\begin{array}{l}\text { UE } \\
\text { PHYS:Glycohb } \\
0 \cdot 17^{*}\end{array}$ & $\begin{array}{l}\text { LE } \\
\text { PHYS:Glycohb } \\
0 \cdot 10\end{array}$ & $\begin{array}{l}\text { UE } \\
\text { SYM:Glycohb } \\
0.07\end{array}$ & $\begin{array}{l}\text { LE } \\
\text { SYM:Glycohb } \\
0 \cdot 13\end{array}$ \\
\hline
\end{tabular}

${ }^{*} \mathrm{p}<0.05 ; \mathrm{tp}<0.015 ;$ †p $<0.001$. 
between physical scores for the median nerve motor and sensory conduction velocities, but not for the ulnar motor velocity. In contrast, both SS and PS were significantly lower in patients with normal values (Class I) of VCAR, H5, H250, and H2000. The most effective discriminator was apparently $\mathrm{H} 5$, which gave the lowest symptom and physical scores corresponding to Class I values.

On the lower extremity, the same tendency prevailed (table 7). NCVs were not very effective discriminators of either symptom or physical scores. Even though NCVTIB did show a significant separation of physical scores, the mean PS for Class I was 38, SD 4, a very high value in the range of moderate impairment, compared to the Class II score of 49, SD 2 . In contrast, CPTs were considerably more effective. Again the

Table 4 Correlation coefficients of NCVs with clinical evaluation

\begin{tabular}{llll}
\hline \multicolumn{3}{c}{ Nerve conduction velocities } \\
\cline { 2 - 4 } & $N C V M$ & $N C V U$ & $N C V S M E D$ \\
\hline $\begin{array}{l}\text { Upper extremity } \\
\text { symptoms }\end{array}$ & $0.15^{*}$ & $0 \cdot 15^{*}$ & $0.15^{*}$ \\
$\begin{array}{l}\text { Upper extremity } \\
\text { physical }\end{array}$ & $0.29 \ddagger$ & 0.13 & $0.19 \dagger$ \\
& $N C V P E R$ & $N C V T I B$ & $N C S S$ \\
\cline { 2 - 4 } $\begin{array}{l}\text { Lower extremity } \\
\text { symptoms }\end{array}$ & 0.04 & 0.07 & $0.28 \ddagger$ \\
$\begin{array}{l}\text { Lower extremity } \\
\text { physical }\end{array}$ & $0.26 \ddagger$ & $0.38 \ddagger$ & $0.15^{*}$ \\
\hline
\end{tabular}

Spearman correlation coefficients for upper extremity symptom and physical scores with median (NCVM) and ulnar (NCVU) nerve motor and median (NCVSMED) nerve sensory conduction velocities and lower extremity symptoms and physical scores with peroneal (NCVPER) and tibial (NCVTIB) motor and sural (NCS) nerve sensory conduction velocities.

${ }^{*} \mathrm{p}<0.05 ; \mathrm{tp}<0.01 ; \ddagger \mathrm{p}<0.001$

Table 5 Correlation of CPTS and VIS with clinical evaluation

\begin{tabular}{|c|c|c|c|c|c|}
\hline & & \multicolumn{4}{|c|}{ Upper extremity CPTS and VTS } \\
\hline & & $V C A R$ & $H S$ & $\mathrm{H} 250$ & H2000 \\
\hline \multicolumn{2}{|c|}{$\begin{array}{l}\text { Upper extremity symptoms } \\
\text { Upper extremity physical }\end{array}$} & $\begin{array}{l}0.28 \ddagger \\
0.35 \ddagger\end{array}$ & $\begin{array}{l}0 \cdot 25 \ddagger \\
0 \cdot 29 \ddagger\end{array}$ & $\begin{array}{l}0.35 \ddagger \\
0.36 \ddagger\end{array}$ & $\begin{array}{l}0 \cdot 29 \ddagger \\
0 \cdot 36 \ddagger\end{array}$ \\
\hline & \multicolumn{4}{|c|}{ Upper extremity CPTS and VTS } & \\
\hline & VIAR & $V T I B$ & $F T 5$ & $F T 250$ & $F T 2000$ \\
\hline \multirow{2}{*}{$\begin{array}{l}\text { Lower extremity } \\
\text { symptoms } \\
\text { Lower extremity } \\
\text { physical }\end{array}$} & 0.03 & 0.05 & $0.22 \dagger$ & $0 \cdot 24 \ddagger$ & $0.25 \dagger$ \\
\hline & $0.45 t$ & $0.48 t$ & $0.53+$ & $0.57 \ddagger$ & $0 \cdot 53 \ddagger$ \\
\hline \multicolumn{6}{|c|}{$\begin{array}{l}\text { Spearman correlation coefficients were calculated for the } \\
\text { relationships of the lower and upper extremity symptom and } \\
\text { physical scores and the given CPTs and VTs. H5, H250, and H2000 } \\
\text { are the CPTs for } 5,250 \text {, and } 2000 \mathrm{~Hz} \text { on the index finger, FT5, } \\
\text { FT250, and FT2000 are the corresponding CPTs on the large toe. } \\
\text { VCAR is the VT on the first metacarpal, VTIB, the VI on the tibial } \\
\text { plateau, and VTAR the VT on the first metatarsal bone. } \\
\text { "p }<0.05 ;+p<0.01 ; \neq p<0.001 \text {. }\end{array}$} \\
\hline
\end{tabular}

Table 6 Comparison of physical and symptom scores for the normal versus the abnormal range of each electrodiagnostic parameter on the upper extremity

\begin{tabular}{|c|c|c|c|}
\hline & & $\begin{array}{l}\text { Physical scores } \\
\text { (SD) }\end{array}$ & $\begin{array}{l}\text { Symptom scores } \\
\text { (SD) }\end{array}$ \\
\hline NCVM & $\begin{array}{l}\text { Normal }(>\mathrm{m} / \mathrm{s}) \\
\text { Abnormal }\end{array}$ & $\begin{array}{l}18(2) \\
26(1) \dagger\end{array}$ & $\begin{array}{l}3 \cdot 0(0 \cdot 3) \\
4 \cdot 0(0 \cdot 2)\end{array}$ \\
\hline NCVU & $\begin{array}{l}\text { Normal }(>50 \mathrm{~m} / \mathrm{s}) \\
\text { Abnormal }\end{array}$ & $\begin{array}{l}22(2) \\
25(2)\end{array}$ & $\begin{array}{l}3.2(0.3) \\
3.8(0.3)\end{array}$ \\
\hline NCSMED & $\begin{array}{l}\text { Normal }(>51 \mathrm{~m} / \mathrm{s}) \\
\text { Abnormal }\end{array}$ & $\begin{array}{l}19(2) \\
25(1)^{*}\end{array}$ & $\begin{array}{l}3 \cdot 1(0.4) \\
3 \cdot 6(0.2)\end{array}$ \\
\hline H5 & $\begin{array}{l}\text { Normal }(<0.58 \mathrm{~mA}) \\
\text { Abnormal }\end{array}$ & $\begin{array}{l}13(3) \S \\
25(1) \dagger\end{array}$ & $\begin{array}{l}2.0(0.4) \S \\
3.6(0.2) \dagger\end{array}$ \\
\hline $\mathrm{H} 250$ & $\begin{array}{l}\text { Normal }(<1.05 \mathrm{~mA}) \\
\text { Abnormal }\end{array}$ & $\begin{array}{l}18(1) \\
27(2) \dagger\end{array}$ & $\begin{array}{l}2 \cdot 5(0 \cdot 3) \\
4 \cdot 1(0 \cdot 2) \dagger\end{array}$ \\
\hline $\mathrm{H} 2000$ & $\begin{array}{l}\text { Normal }(<2.7 \mathrm{~mA}) \\
\text { Abnormal }\end{array}$ & $\begin{array}{l}18(2) \\
27(2) \dagger\end{array}$ & $\begin{array}{l}2 \cdot 7(0.3) \\
4.0(0.2) \dagger\end{array}$ \\
\hline VCAR & $\begin{array}{l}\text { Normal }(<8 \mathrm{mV}) \\
\text { Abnormal }\end{array}$ & $\begin{array}{l}19(2) \\
26(3) \dagger\end{array}$ & $\begin{array}{l}2 \cdot 6(0 \cdot 3) \\
4 \cdot 1(0 \cdot 2) \dagger\end{array}$ \\
\hline
\end{tabular}

Physical scores (PS), totalled as described, and symptom scores (SS) on a 0 to 10 scale, are given. The higher the score, the more severe the symptoms and physical impairments. A PS of 0 is normal, 1-16: mild neuropathy, 17-47: moderate neuropathy, and 48 or greater: severe neuropathy. The SS and PS corresponding to electrodiagnostic readings in the normal range are compared with the scores corresponding to electrodiagnostic values outside the normal range. The boundary limiting value for the normal range of each electrodiagnostic parameter is given in parentheses. ${ }^{*}: p+0.05$; $t p<0.01$. The values in parenthesis with $\S$ superscripts indicate which electrodiagnostic parameter had the lowest symptom or physical score for the normal range $\S: p<0.05$

Table 7 Comparison of physical and symptom scores for the normal versus the abnormal range of each electrodiagnostic parameter on the lower extremity

\begin{tabular}{llll}
\hline & & $\begin{array}{l}\text { Physical scores } \\
(S D)\end{array}$ & $\begin{array}{l}\text { Symptom scores } \\
(S D)\end{array}$ \\
\hline NVCPER & Normal $(>41 \cdot 5 \mathrm{~m} / \mathrm{s})$ & $44(3)$ & $5 \cdot 2(0 \cdot 4)$ \\
& Abnormal & $49(2)$ & $5 \cdot 0(0 \cdot 2)$ \\
NCVTIB & Normal $(>41 \mathrm{~m} / \mathrm{s})$ & $38(4) \dagger$ & $5 \cdot 3(0 \cdot 4)$ \\
& Abnormal & $49(2)$ & $5 \cdot 0(0 \cdot 2)$ \\
NCSS & Normal $(>41 \mathrm{~m} / \mathrm{s})$ & $39(4)$ & $7 \cdot 2(0 \cdot 5)$ \\
& Abnormal & $48(2)$ & $5 \cdot 0(0 \cdot 2)$ \\
VTAR & Normal $(<9 \mathrm{mV})$ & $35(17)$ & $5 \cdot 0(2 \cdot 1)$ \\
& Abnormal & $48(2)$ & $5 \cdot 2(0 \cdot 2)$ \\
VTIB & Normal $(<9 \mathrm{mV})$ & $33(14)$ & $4 \cdot 0(2 \cdot 3)$ \\
& Abnormal & $48(2)$ & $5 \cdot 2(0 \cdot 2)$ \\
FT5 & Normal $(<0.9 \mathrm{~mA})$ & $15(5) \S$ & $2 \cdot 4(0 \cdot 6) \S$ \\
& Abnormal & $49(2) \dagger$ & $5 \cdot 3(0 \cdot 2)$ \\
FT250 & Normal $(<1.2 \mathrm{~mA})$ & $16(4)$ & $3.3(0 \cdot 5)$ \\
& Abnormal & $50(2) \dagger$ & $5 \cdot 3(0 \cdot 2) \dagger$ \\
FT2000 & Normal $(<3.6 \mathrm{~mA})$ & $27(4)$ & $4 \cdot 3(0 \cdot 5)$ \\
& Abnormal & $51(2)^{*}$ & $5 \cdot 3(0 \cdot 2)$ \\
\hline
\end{tabular}

Physical scores (PS), totalled as described, and symptom scores (SS), on a 0 to 10 scale, are given. The higher the score, the more severe the symptoms and physical impairments. A PS of 0 is normal, 1-16: mild neuropathy, 17-47: moderate neuropathy, and 48 or greater: severe neuropathy. The SS and PS corresponding to electrodiagnostic readings in the normal range are compared to the scores corresponding to electrodiagnostic values outside the normal range. The boundary limiting value for the normal range of each electrodiagnostic parameter is given in parentheses. *: $p<0.05$; tp $<0.01$. The values in parenthesis with $\S$ superscripts indicate which electrodiagnostic parameter had the lowest symptom or physical score for the normal range $\$ p<0.05$. 
$5 \mathrm{~Hz}$ frequency, FT5, gave the lowest Class I values for both symptom $(2 \cdot 4$, SD $0 \cdot 6)$ and physical (15, SD 5) scores. VTs were not effective on the lower extremity either in discriminating physical or symptom changes.

It could be argued that our class comparisons were skewed by a large proportion of very abnormal or unobtainable measures for certain electrodiagnostic parameters. To exclude this possibility, the clinical score comparisons were repeated, subdividing abnormal NCVs, CPTs, and VTs into "relatively abnormal" (Class IIa) and "very abnormal" (Class IIb) values. In so doing, any NCV value $10 \mathrm{~m} / \mathrm{s}$ below the lower limit of the abnormal range or unobtainable NCV was segregated into Class IIb as were CPT values greater than $9 \mathrm{mAmp}$ and VTs greater than 35 volts. The repeat contrast analysis did show significant differences in PS values between Class I and Class IIb for NCSMED, NCVPER, NCSS, VTAR, and VTIB, but not for the SS values (figs 1 and 2). Class IIa NCVs showed no differences in SS and PS values from Class I NCVs, with the sole exception of NCVM. In contrast, Class IIa CPTs in almost all cases showed significant differences in both SS and PS from Class I CPTs (figs 1 and 2).

\section{Discussion}

Nerve conduction testing is currently the standard procedure for diagnostic evaluation of diabetic neuropathy. The clinical question usually addressed by nerve conduction testing is whether or not diabetic neuropathy is present, and this technique has been effective in answering the question. ${ }^{46} \mathrm{~A}$ far more subtle issue is whether nerve conduction velocities correlate sufficiently to the level of clinical impairment to furnish a quantitative indicator useful for comparison and follow up, in particular for the evaluation of sensory abnormalities.

The greatest difficulty in study design to evaluate this issue lies in the ability to define "clinical severity" of sensory neuropathy. Motor impairment is somewhat easier to define objectively than abnormal sensation. The NSS and NDS scoring system relies on a preponderant contribution of motor rather than sensory assessments. ${ }^{47}$ In the present study, clinical evaluation of sensory function was the main emphasis. This clinical evaluation was then systematically categorised and stratified by both neurological history and physical examination data, evaluated separately. Careful and thorough quantitation of symptom evaluation and neurological physical exam was essential. Historical data are quite subjective, conditioned by patient as well as interviewer perception. Very painful diabetic neuropathy may justifiably be perceived as "severe", but is it more severe than asymptomatic anesthaesia below the knees and elbows? We attempted to establish historical criteria to minimise variability. Furthermore, the physical examination was carried out in highly structured, reproducible fashion, on a large number of anatomic sites, with a well defined categorisation procedure.

Electrodiagnostic testing is also subject to significant variability. Nerve conduction testing was repeated within several days of each test, whenever possible, to minimise variability. Perhaps the most substantial safeguard against subjective and procedural variations was the repeated serial evaluations of a significant percentage of the study subjects.

Having taken these steps to improve the quality of the quantitative comparisons, our results suggest that NCVs are far from an ideal parametric indicator in diabetic sensory neuropathy. Although the correlations between detailed historical and physical scoring and most NVCs are significant, the degrees of correlation do not appear sufficient to create adequate distinctions among the various strata of clinically observable impairment. Indeed, the first level of contrast is between the normal and abnormal range of NCVs. Here, with the relative exception of the median nerve motor nerve conduction velocity, most NCVs failed to provide significant clinical distinctions.

Similar findings have been reported by other investigators. Halar and associates found no difference in median sensory, sural sensory, and tibial motor NCVs between diabetics with and without clinical signs of diabetic neuropathy. ${ }^{47}$ Lamontagne and Buchthal found a significant correlation between clinical signs and symptoms and peroneal nerve motor nerve conduction velocities, but not with median nerve motor or sensory NCVs. ${ }^{46}$

Dyck et al have found significant correlations between NCVs and NSS and NDS scores. ${ }^{48}$ The levels of correlation they reported have been somewhat higher than in the present study, particularly for the symptom scoring using the NSS, perhaps reflecting the very high contribution of motor abnormalities to the NSS and NDS system they use. Nevertheless, the levels of correlation have likewise been insufficient for specific clinical gradation. For example, they reported that abnormality of nerve conduction of a single nerve is associated with only $26 \%$ abnormality of NSS and only $11 \%$ of NDS in their simultaneous evaluation. ${ }^{49}$ Abnormality of two nerves raises this percentage to $47 \%$ and $42 \%$, respectively. Only with abnormality of both upper and lower extremity nerve conduction does the percentage rise to $97 \%$ and $95 \%$, respectively. They furthermore concluded that the clinical state can not be predicted by knowing the clinical severity of the nerve conduction abnormality. They reported a lower correlation of vibratory threshold with clinical evaluation than for NCVs, unlike the findings of the present study. This difference may again reflect the large 

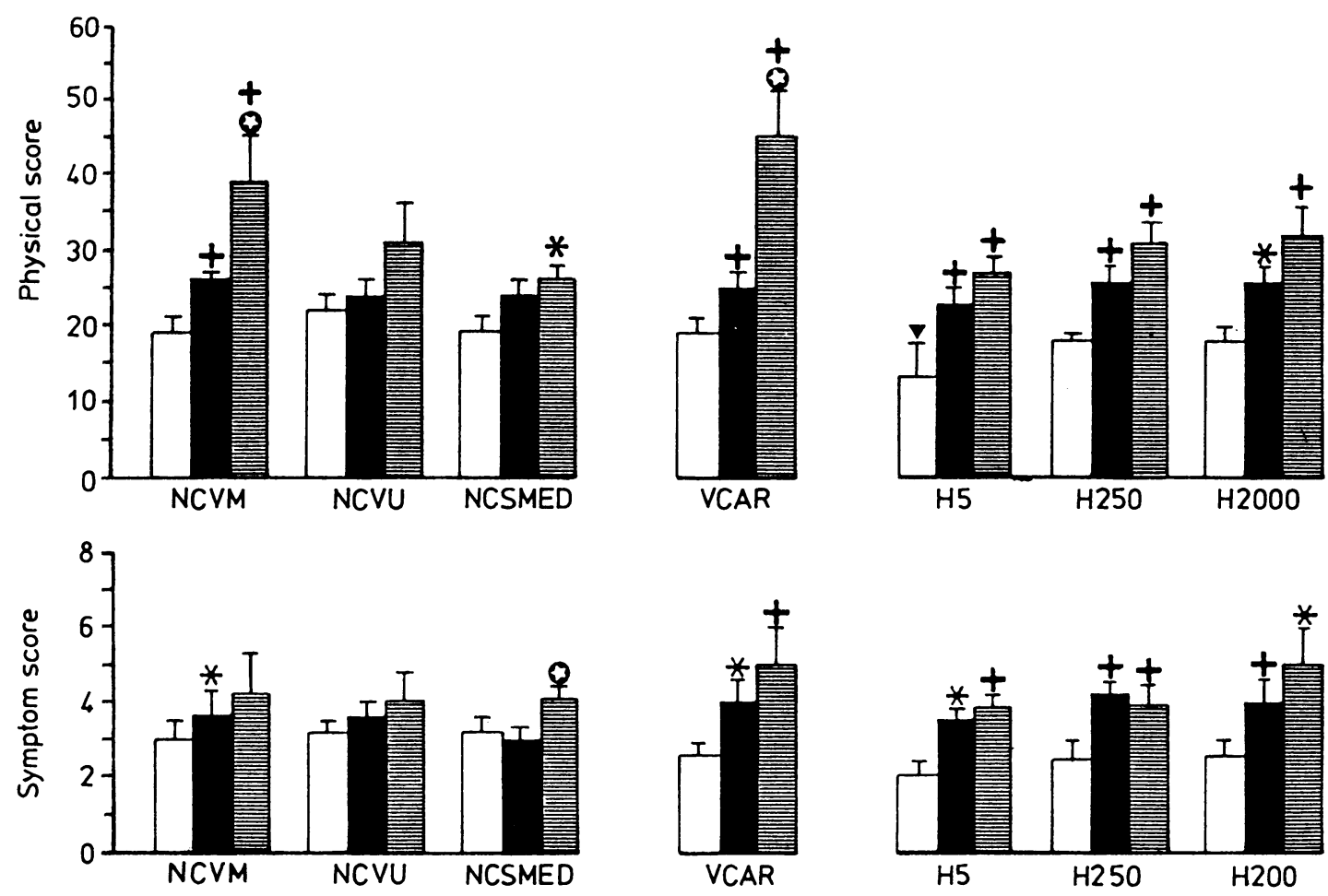

Fig 1 Comparison of symptom and physical scores for the three electrodiagnostic techniques on the upper extremity: scores (mean with standard error) are given corresponding to electrodiagnostic values subdivided into the three ranges: Class I (Normal) [Clear Bar]. Class IIa (Relatively Ahnormal) [Black Bar], and Class IIb (Very Ahnormal) [Hatched Bar]. Statistically significant comparisons: Cross: $p<0.01$ as compared to Class I: Star: $p<0 \cdot 05$ as compared to Class IIa: Asterix: $p<0.05$ compared to Class I; Inverted triangle: $p<0.05$ as compared to the other Class I electrodiagnostic parameters.

contribution of motor function to the NSS and NDS, in contrast to the modifications made in the present study to emphasise sensory function.

It is not at all difficult to understand why the clinically observable level of sensory neuropathy and nerve conduction velocities should show quantitative divergence. Standard nerve conduction velocity testing measures mainly the contribution of the largest, most rapidly conducting fibres while the sensations are subserved by small diameter, slower conducting axons. Therefore, although nerve conduction velocities may be a good indicator of the neuropathic process affecting the large axons, they very likely fail to reflect the state of the smaller axons which may correlate better with clinical state.

The failure to correlate highly with quantitative clinical parameters is a problem if the goal is to assess a form of treatment for the clinical condition of diabetic sensory neuropathy. For example, although there is significant increase in motor nerve conduction velocities after improved glycaemic control in diabetic patients, it has not been demonstrated that this improvement in NCVs is associated with clinical improvement in the neuropathy. ${ }^{50-55}$ In several studies to date of both myoinositol and aldose reductase inhibitors in diabetic sensory neuropathy, the questionable relationship between clinical findings and $\mathrm{NCV}$ measurements has led to confusiion as to the true efficacy of the agents tested. ${ }^{56-60}$ Improvements in NCVs occur in asymptomatic patients. Conversely clinical improvement had occurred, unaccompanied by improvements in NCVs.

In the present study, local techniques such as vibration and current perception testing showed better correlations with sensory clinical parameters than nerve conduction testing. That is not surprising since these techniques rely upon local perception as well as axonal conduction, just as do the physical parameters of pain and temperature. CPT measurements were particularly effective as discriminators of both symptomatic and physical status. Although correlations were not perfect with SS and PS, they were sufficient to 

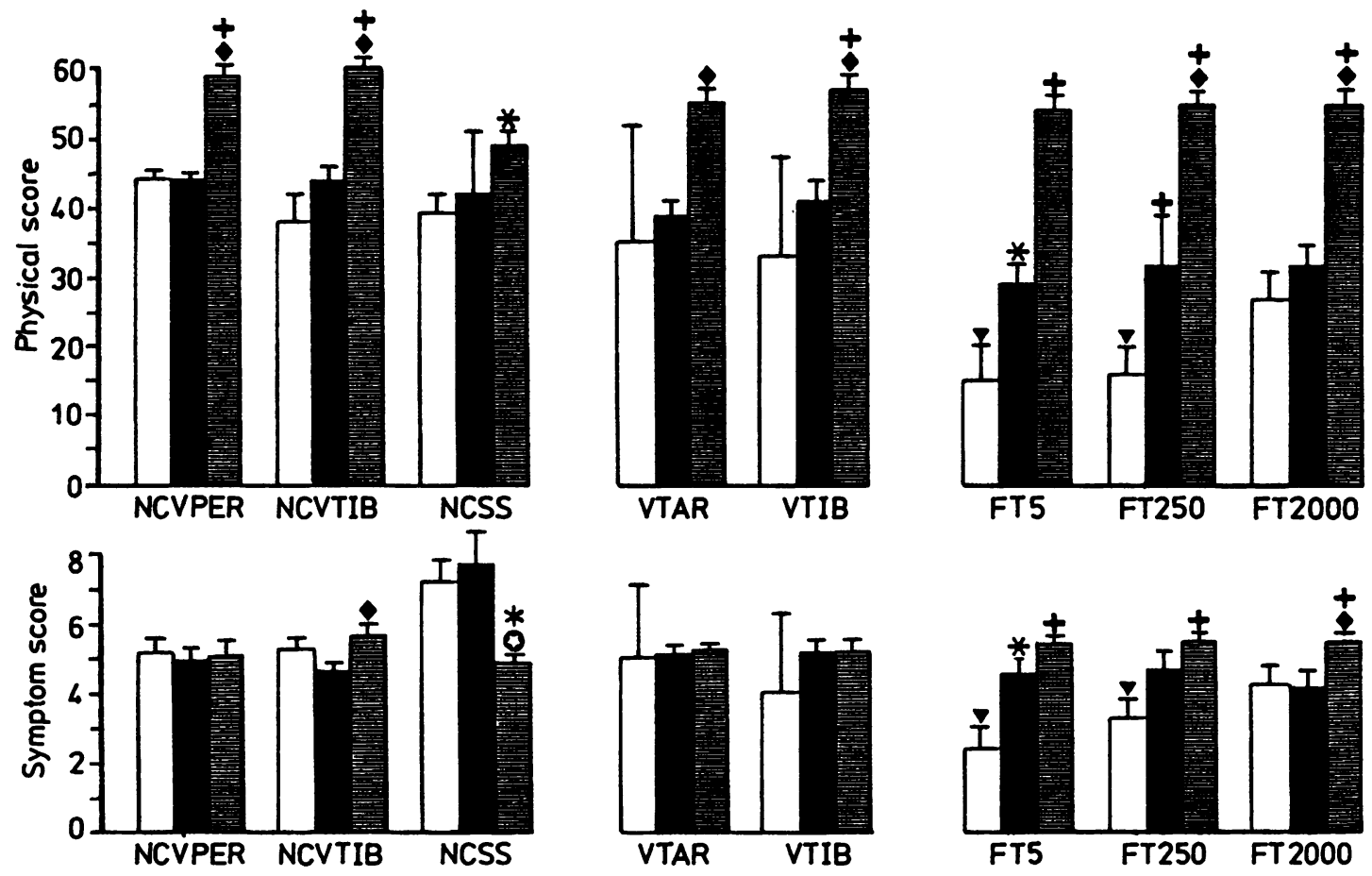

Fig 2 Comparison of symptom and physical scores for the three electrodiagnostic techniques on the lower extremity: scores (mean with standard error) are given corresponding to electrodiagnostic values subdivided into the three ranges: Class I (Normal) [Clear Bar], Class IIa (Relatively Abnormal) [Black Bar], and Class IIb (Very Abnormal) [Hatched Bar]. Statistically significant comparisons: Cross: $p<0.01$ as compared to Class I; Star: $p<0.05$ as compared to Class IIa; Asterix: $p<0.05$ compared to Class I; Inverted triangle: $p<0.05$ as compared to the other Class I electrodiagnostic parameters.

produce significant discrimination of clinical status. It should be noted that CPT testing was performed only on two sites, the finger and the toe, in individuals with significant distal neuropathy. It may be that addition of more proximal testing sites might refine the comparisons of clinical status even further, and further increase coefficients of correlation. Even with the limited CPT testing carried out in the present study, correlations with clinically meaningful parameters were substantially greater than those obtained with NCVs.

It is interesting that a clear frequency selectivity was demonstrable in the CPTs. The lowest frequency, $5 \mathrm{~Hz}$, appeared to be the most effective indicator. The concept of frequency selectivity of neuronal response to alternating current deserves further exploration. Perhaps a wider range of frequencies may further improve the diagnostic correlative accuracy of the CPT evaluation in diabetic sensory neuropathy.

It would appear that inclusion of CPT testing in the design of clinical trials of therapeutic agents for diabetic neuropathy may be beneficial. Such tech- niques may improve the assessments provided by nerve conduction testing.

This work was partially supported by a grant from the Diabetes Research and Education Foundation, Bridgewater, NJ and the Health Future Foundation, Omaha, Nebraska.

\section{References}

1 Pirart J. Diabetes mellitus and its degenerative complications: A prospective study of 4,400 patients observed between 1947 and 1973. Diabetes Care 1978;1:168-88.

2 Gilliatt RW, Willison RG. Peripheral nerve conduction in diabetic neuropathy. J Neurol Neurosurg Psychiatry 1963;25:11-18.

3 Downie AW, Newell DJ. Sensory nerve conduction in patients with diabetes mellitus and controls. Neurology 1961;11:876-82.

4 Mulder DW, Lambert EH, Bastron JA, Sprague RG. The neuropathies associated with diabetes mellitus. A clinical and elctromyographic study of 103 unselected diabetic patients. Neurology 1961;11:275-84.

5 Skillman TG, Johnson EW, Hamwi GJ, Driskill HF. Motor nerve conduction velocity in diabetes mellitus. Diabetes 1961;10: 
46-51.

6 Lawrence DG, Locke S. Motor nerve conduction velocity in diabetes. Arch Neurol 1961;5:483-9.

7 Gregersen G. Diabetic neuropathy: Influence of age, sex, metabolic control, and duration of diabetes on motor conduction velocity. Neurology 1967;17:972-980.

8 Lambert EH, Dyck PJ. Compound action potentials of sural nerve in vitro in peripheral neuropathy. In: Dyck PJ, Thomas PK, Lambert EH, eds. Peripheral Neuropathy. Philadelphia: WB Saunders, 1975:427-41.

9 Thomas PK, Lascelles RG. The pathology of diabetic neuropathy. Q J Med 1966;35:489-509.

10 Thomas PK. The morphological basis for alterations in nerve conduction peripheral neuropathy. Proc $R$ Soc Med 1971;64: 13-16.

11 Dyck PJ. Pathological alterations of the peripheral nervous system of man. In: Dyck PJ, Thomas PK, Lambert EH, eds. Peripheral Neuropathy. Philadelphia: WB Saunders, 1975;296-336.

12 Behse F, Buchthal F, Carlsen F. Nerve biopsy and conduction studies in diabetic neuropathy. J Neurol Neurosurg Psychiatry 1977; 40:1072-82.

13 Brown MJ, Martin JR, Asbury AK. Painful diabetic neuropathy. A morphometric study. Arch Neurol 1966;33:164-171.

14 Greene DA, Brown MJ, Braunstein SN, Schwartz SS, Asbury AK, Winegrad AI. Comparison of clinical course and sequential electrophysiological tests in diabetics with symptomatic polyneuropathy and its implications for clinical trials. Diabetes 1981;30:139-47.

15 Pfeiffer EA. Electrical stimulation of sensory nerves with skin electrodes for research, diagnosis, communication, and behavioural conditioning: a survey. Med Biol Eng Comput 1968; 6:637-45.

16 Sigel H. Cutaneous sensory threshold stimulation with high frequency square wave current I. The relationship of electrode dimensions to the sensory threshold. $J$ Invest Dermatol 1952; 18:441-5.

17 Sigel $\mathrm{H}$. The relationship of body site and of skin disease to the sensory threshold. J Invest Dermatol 1952;18:447-51.

18 Tursky B, Watson PD. Controlled physical and subjective intensities of electric shock. Psychophysiol 1964;1:151-62.

19 Gougerot $L$. The electrical equivalent circuit of the human skin. $J$ Radiol 1968:29:479-486.

20 Davis RT, Kennard DW. Influence of electric current on the skin. Nature 1962;193:1186-7.

21 Joss G. An unusual phenomenon in the electrical properties of mammalian skin. Nature 1964;201:418-9.

22 Conomy JP, Barnes KL. Quantitative assessment of cutaneous sensory function in subjects with neurologic disease. $J$ Neurol Sci 1976;30:221-35.

23 Conomy JP, Barnes KL, Conomy JM. Cutaneous sensory function in diabetes mellitus. J Neurol Neurosurg Psychiatry 1979; 42:656-61.

24 Linzer M, Long D. Transcutaneous neural stimulation for relief of pain. IEEE Trans Biomed Eng 1976;BME-23:341-5.

25 Sjolund $\mathrm{BH}$, Erikson MBE. The influence of naloxone on analgesia produced by peripheral conditioning stimulation. Brain Res 1979;173:295-301.

26 Hahn JF. Cutaneous vibratory thresholds for square wave electrical pulses. Science 1958;127:878-9.

27 Seligman LJ. Physiological stimulators: from electric fish to programmable implants. IEEE Trans Biomed Eng 1982;BME 29(4): $270-84$.

28 Burton C, Maurer PD. Pain suppression by transcutaneous electric stimulation. IEEE Trans Biomed Eng 1974;21:81--8.

29 Mueller EL. Loeffel R, Mead S. Skin impedance in relation to pain threshold testing by electrical means. J Appl Physiol 1952;5: 746-52.

30 Notermans SL. Measurement of the pain threshold determined by electrical stimulation and its clinical application. Part I. Method and factors possibly influencing the pain threshold. Neurol 1966;
16:1071-86

31 Butikofer R, Lawrence PD. Electrocutaneous nerve stimulation I Model and Experiment. IEEE Trans Biomed Eng 1978;BME 25 : 526-31.

32 Butikofer R, Lawrence PD. Electrocutaneous nerve stimulation II: Stimulus waveform selection. IEEE Trans Biomed Eng 1979, BME 26:69-75.

33 Bostock H, Sears TA, Sheratt RM. The spatial distribution of excitability and membrane current in normal and demylinated mammalian nerve fibers. $J$ Physiol (Lond) 1983;341:41-58.

$34 \mathrm{McNeal}$ DR. Analysis of a model for excitation of myelinated nerve. IEEE Trans Biomed Eng 1976;BME 23:329-37.

35 Reilly JP, Freeman VT, Larkin WD. Sensory effects of transients electrical stimulation-Evaluation with a neurolelectric model. IEEE Trans Biomed Eng 1985;BME 32:1001-11.

36 Katims JJ, Long DM, Ng LKY. Transcutaneous nerve stimulation (TNS): frequency and waveform specificity in humans. Appl Neurophysiol 1986;49:86-91.

37 Katims JJ, Naviasky E, Ng LKY, Rendell M, Bleecker M. A new screening device for the assessment of peripheral neuropathy. J Occup Med 1986;28:1219-21.

38 Katims JJ, Naviasky EH, Rendell MS, Ng LKY, Bleecker ML. Constant Current Sine Wave Transcutaneous Nerve Stimulation for the Evaluation of Peripheral Neuropathy. Arch Phys Med Rehab 1987;68:210-3.

39 Steiness I. Vibratory perception in normal subjects. A biothesiometric study. Acta Med Scand 1957;158:315-25.

40 Steiness I. Vibratory perception in diabetics. A biothesiometric study. Acta Med Scand 1957;158:327-35.

41 Gregersen G. Vibratory perception threshold and motor conduction velocity in diabetics and non-diabetics. Acta Med Scand 1968;183:61-5.

42 Dyck PJ, Sherman WR, Hallcher M, et al. Human diabetic endoneurial sorbitol, fructose, and myoinositol related to surak nerve morphometry. Ann Neurol 1980;8:590-6.

43 Kimura J. Electrodiagnosis in Diseases of Nerve and Muscle Principles and Practice. Philadelphia: FA Davis, 1983.

44 Goldberg JM, Lindblom U. Standardised method of determinin vibratory perceptions thresholds for diagnosis and screening in neurological investigation. J Neurol Neurosurg Psychiatry 1979 42:793-803.

45 Snedecor GW, Cochran WG. Statistical methods. 6th Ed. Ames, Iowa, Iowa State University Press, 1967.

46 Lamontagne A, Buchthal F. Electrophysiological studies in diabetic neuropathy. J Neurol Neurosurg Psychiatry 1970;33: 442-52.

47 Halar EM, Graf RJ, Halter JB, Brozovich FV, Soine TL. Diabetic neuropathy: a clinical, laboratory and electrodiagnostic study. Arch Phys Med Rehab 1982;63:298-303.

48 Dyck PJ, Karnes JL, Daube JR, O'Brien PC, Service FJ. Clinical and neuropathological criteria for the diagnosis and staging of diabetic polyneuropathy. Brain 1985;108:861-80.

49 Dyck PJ, Bushek W, Spring EM, Karnes JL, Litchy WJ, O'Brien PC, Service FJ. Vibratory and cooling detection thresholds compared with other tests in diagnosing and staging diabetic neuropathy. Diabetes Care 1987;10:432-440.

50 Gregersen G. Variations in motor conduction velocity produced by acute changes of the metabolic state in diabetic patients. Diabetologia 1968;4:273-7.

51 Ward JD, Barnes CG, Fisher DJ, Jessop JD, Baker RWR Improvement in nerve conduction following treatment in newly diagnosed diabetics. Lancet 1971;1:428-30.

52 Fraser DM, Campbell IW, Ewing DJ, Murray A, Neilson JMM, Clarke BF. Peripheral and autonomic nerve function in newly diagnosed diabetes mellitus. Diabetes 1977;26:546-50.

53 Graf RJ, Halter JB, Pfeifer MA, Halar EM, Brozovich F, Porte D. Glycemic control and nerve conduction abnormalities in noninsulin dependent diabetic subjects. Ann Int Med 1981;94: 307-11.

54 Porte D, Graf RJ, Halter JB, Pfeifer MA, Halar E. Diabetic 
neuropathy and plasma glucose control. Am J Med 1981;70: 195-200.

55 Pietri A, Ehle AL, Raskin P. Changes in nerve conduction velocity after six weeks of glucoregulation with portable insulin infusion pumps. Diabetes 1980;29:668-71.

56 Handelsman DJ, Turtle JR. Clinical trial of an adiose reductase inhibitor in diabetic neuropathy. Diabetes 1981;30:459-464.

57 Fagius J, Jameson S. Effects of aldose reductase inhibitor treatment in diabetic polyneuropathy - a clinical and neurophysiological study. J Neurol Neurosurg Psychiatry 1981;44:
991-1001.

58 Gabbay KH, Speck N, Loo S, Hirsch HJ, Ackil AA. Aldose reductase inhibition: studies with Alrestatin. Metabolism 1979; 28:Suppl 1:471-6.

59 Culebras A, Alio J, Herrera JL, Lopez-Fraile IP. Effect of an aldose reductase inhibitor on diabetic peripheral neuropathy: preliminary report. Arch Neurol 1981;38:133-4.

60 Judzewitsch RG, Jaspan JB, Polonsky KS, et al. Aldose reductase inhibition improves nerve conduction velocity in diabetic patients. N Engl J Med 1983;308:119-25.

\section{Some remarks on the work of Andrew Connal: A study of cerebrospinal fluid in meningitis}

"In a series of investigations based upon the examination of cerebrospinal fluid flowing spontaneously from the nose of a girl with a tumour of the brain, and numerous other cases, as meningitis and so on, I found-mercury, iodides, and salicylates given by the mouth, cutaneously or subcutaneously, do not pass into the cerebrospinal fluid, as I showed conclusively in a series of exact experiments, and this fact is of fundamental importance as regards the whole subject of the absorption process in the brain."

v Jaksch, R. Q J Med 1909-10;3:296.

RT ROSS

The importance of optic neuritis and retinal haemorrhages in the diagnosis of chronic septic endocarditis

"In the acute cases, especially those of puerperal origin, and in the more or less acute cases complicating with suppurative meningitis and cerebral abscess, panophthalmitis, embolism of the central artery of the retina, optic neuritis, and the retinitis septica of von Roth, have been frequently met with, but in the literature at my command $I$ have been able to find few references to the occurrence of double optic neuritis (papilloedema), apparently a toxaemic manifestation, comparatively early in the history of the chronic form of the disease."

Falconer, AW. Q J Med 1909-10;3:107-14.

RT ROSS

The respiratory movements in hemiplegia

"In ordinary breathing the following peculiarities are observed on the paralyzed side.

1. The respiratory excursion both inspiratory and expiratory is much diminished, ie the height of the wave is reduced.

2. The character of the wave is altered.

(a) It is much rounder.

(b) It is delayed, for the rise may not begin until that on the sound side is $3 / 4$ to $5 / 6$ complete.

(c) It is shorter, so that the post-expiratory pause, which hardly exists on the sound side, is very obvious.

In voluntary breathing the differences are the same kind but exaggerated.

On coughing (c) the curves move in opposite directions, for a while on the sound side after somewhat exaggerated inspiration the chest contracts, the paralyzed side instead of contracting it is distended by the coughing, and the more powerful the cough the greater the distention or bulging."

West, Samuel. Q J Med 1907-08;1:448-53.

RT ROSS

\section{Diphtheritic paralysis}

"There seems then to be a two-fold mechanism in the production of diphtheritic paralysis in man. There is the initial sometimes severe and relatively short-lived "local" paralysis, due to the action of the toxin, which has ascended the nerve innervating the local lesion, on the nerve nuclei in the brainstem. Secondly, there is the later, longer lasting "generalised" paralysis which is part of the general systemic toxaemia."

Walshe, FMR. On the Pathogenesis of Diphtheritic Paralysis. Q J Med 1918;11:191-204.

RT ROSS

\section{Thromboangitis obliterans}

"In regard to the possible contributory influence of cigarette-smoking in this disease, I wish to emphasize that I have never come across an instance of the disease in a woman, nor yet in a man who is not, or has not been, a free cigarette smoker. Moreover, my observations and enquiries make certain that the women of the Jewish families in the East End of London are practically all absolute abstainers from tobacco. Smoking amongst these women is unknown and unheard of, though their menfolk are so notoriously fond of it."

Parkes-Weber, F. Thromboangiitis obliterans (non-syphilitic arteritis obliterans of Hebrews). $Q J$ Med 1916;36:289-300. 